\title{
Role Of Probability Biclassification In Accounting And Finance Random Variable Representations
}

\author{
Charmaine Scrimnger-Christian, North-West University (VTC), South Africa
} Saratiel Wedzerai Musvoto, North-West University (VTC), South Africa

\begin{abstract}
The concept of value in accounting has been generalized by various authors to a large variety of relations in both accounting and finance. For example, the basis for the preparation of the financial statements in accounting and the foundations for the determination of the return on a security in finance are based on the concept of value measurement. However, there are cases in which applications of the concept of value measurement breaks down, such as in predicting the long-run behavior of accounting and finance phenomena classified as random variables and in applying deterministic models to accounting and finance models. In this study, the principles of probability biclassification and random utility theory are used to rectify the shortcomings of generalizing the concept of value measurement to include activities to understand the long-run behavior of random variables. This study closes with a discussion on the compatibility of the intentionality structure of acts of knowledge in accounting and finance with statistical concepts on random variables.
\end{abstract}

Keywords: Random Variables; Probability Biclassification; Intentionality Structure; Subjectivity

\section{INTRODUCTION}

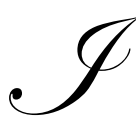
$\mathrm{n}$ accounting and finance tendencies to prefer rules over unconstrained judgments are abound. This has been brought about by the need in these disciplines to be more aligned with natural sciences than with social sciences. For example, in the finance discipline, deterministic models such as the Black, Jensen and Scholes (1973) option pricing model, and the binominal option pricing model (Haugens, 2001) prescribe consistent rules for pricing securities. A random prescription of rules would result in option prices that have no specific boundaries. In the accounting discipline, the assignment of monetary units to the elements of the financial statements is governed by bases of measurement. According to the IASB (2009), one can employ historical cost, current cost, realisable value and present value to different degrees and in varying combinations in the financial statements. It is clear then that in the assignment of monetary units to the elements, the financial statements are done according to fixed quantitative rules. If this is the case, it may be argued that unconstrained judgments in social sciences bring vague and ambiguous multi-perspectives to issues that are difficult to reconcile. According to Heelan (1965), the free exercise of judgment invites suspicion of arbitrariness or bias. As a result, it may be argued that accounting and finance have adopted quantitative rules in order to improve the objectivity of the information they produce. Moreover, Stevens (1951) points out that the stature of an empirical science is measured by the extent to which it employs quantitative rules. Hence, it may be suggested that fixed quantitative rules are employed in accounting and finance in order to improve their statures as empirical sciences.

In the finance discipline, the use of the concept of a random variable in predicting the price of a security over a period of time implies a scientific knowing on each individual occurrence of the price of a security. In investment theory the simple probability distribution for an investment shows the probabilities of getting various rates of return over the course of a particular period of time (Haugens, 2001), e.g., a month. Clearly, the sample space is defined by incorporating outcomes of experiments that have been performed at different points in time. 
According to Heelan (1965), a random set is a finite sample of elements, which are individual, concrete and independent instances of the same ideal norm. Consequently, if each event in the sample space has an equal chance of happening within a particular period of time, then, it may be argued that time is considered irrelevant in that experiment. If it is, then the performance of an experiment at different times would result in events that are not independent instances of the same ideal norm. They will not be part of the same random set.

Although the use of quantitative rules is believed to improve the stature of an empirical science, it is also important to note that there are rules governing the employment of quantitative rules. According to Heelan (1965), fixed quantitative rules are employed in empirical sciences only in instances of scientific knowing. This means that the employment of fixed quantitative rules in accounting and finance imply the presence of scientific knowing of the particulars of accounting and finance phenomena. In this case, it may be argued that scientific knowing is characterized by the specification of the empirical properties that are useful in identifying and measuring the attributes of the phenomenon in question. However, research in accounting (see Musvoto, 2008; Musvoto \& Gouws 2010; Musvoto \& Scrimnger-Christian, 2010; Musvoto, 2011 and Staubus, 2004) indicates that there is no evidence to support the existence of scientific knowing of the particulars of finance and accounting events whose attributes are subject to measurement. This suggests that fixed quantitative rules are applied in accounting and finance to situations that do not call for their use.

In view of the above, the purpose of this study is to highlight problems associated with the generalization of the concept of value measurement, to include cases that require the prediction of the long-run behavior of accounting and finance phenomena classified as random variables and the use of deterministic models in predicting the behavior of accounting and finance phenomena. This study commences with a literature review in Section 2 . This is followed by an address and prescription of possible solutions to the problems associated with representing perceived random variables in accounting and finance with probability distributions in Section 3. In Section 4, the intentionality structure of the acts of knowledge in accounting and finance are discussed. Section 5 concludes the study.

\section{LITERATURE REVIEW}

The phraseology of accounting and finance concepts imply the existence of random phenomena in the disciplines. According to Zebda (1991), randomness deals with the probabilistic uncertainty concerning the occurrence or non-occurrence of an event. Therefore, the particulars of the event are known, but it is only the particulars of the values that it will assume on its next occurrence that are not known. In the accounting discipline the viewpoint is that the particulars of accounting events are known but the values it will assume on its next occurrence are not known. For example, the terminology used in the accounting discipline implies the existence of random variables in the discipline, e.g. the IASB (2009, Para 49) framework defines an asset as "a resource controlled by the entity as a result of past events and from which future economic benefits are expected to flow to the entity".

This definition indicates that the particulars of an asset are known by the defining entity as it is a resource controlled by the entity in the present. Moreover, the excerpt highlights that the concept of expected economic benefits implies uncertainty in the benefits that are expected to flow to the entity. In this case, it may be argued that the accounting conceptual framework asserts that in order to achieve recognition the value of the asset must be determined using probabilistic concepts. As a result it may be assumed that the definition of an asset implies that the particulars of the event are known in advance, but there is uncertainty as to the outcome of the future economic benefits. In this case, the quantification of future economic benefits determines the value of an asset at a particular point in time. There are other instances in which the accounting conceptual framework describes the existence of random variables in the accounting discipline such as the concepts of liability (IASB, 2009, Para 60), income (IASB, 2009, Para 70) and equity (IASB, 2009, Para 65), to name a few. The common theme in the definitions is that they imply knowledge of the event in its particularity but highlight a lack of knowledge of the values it will assume on its next occurrence. Hence, the definitions imply that the elements of the financial statements are random variables.

In the finance discipline the existence of random variables is implied. For example, the particulars of a security are believed to be known, but it is only the value that the security will assume that is not known implying 
that it fits the profile of a random phenomenon. For instance, Haugens (2001) points out that the potential for getting various rates of return on a security over a period of time is given by a simple probability distribution. The concept of a simple probability distribution assumes that there is a series of discreet possible rates of return each associated with a specific probability. In this case the security may adopt any of these values, but at that point in time it is not known which one it will assume. For this reason, it can be argued that this viewpoint implies that there is an established law that governs how these probabilities are determined.

However, criticisms have been leveled against the concept of random variables in accounting and finance. For example, Musvoto $(2008,2011)$ notes that value is the attribute of the elements considered measurable. He criticizes the fact that value in the accounting discipline is represented by monetary units in the absence of a specified set of homomorphisms that map the empirical structure of value onto monetary units. The absence of homomorphisms places little restriction on the uniqueness of representations, i.e. this places little restriction on the structure beyond monetary units and cardinality. If this is the case, it is not possible to know conclusively the structure and empirical properties of value. Therefore, it cannot be considered a random variable. Moreover, Musvoto and Scrimnger-Christian (2010) point out that the concept of a random variable introduces the concept of probability in the measurement of its possible assumed values in the future. This introduces to any discipline using the concept of a random variable all the problems associated with the concept of probability. For instance, Musvoto (2011) asserts that the introduction of the concept of probability to accounting and finance phenomena creates problems concerning the treatment of error that are intimately connected with the concept of measurement in these disciplines. In particular, it is noted that there is currently no mechanism in the accounting discipline to test the measurement axiomatizations that underlie probabilities. According to Falmagne $(1979,1980)$ and Michell $(1986)$, this problem is exacerbated by the fact that the modern principles of measurement theory have not made much progress in devising a system that tests the measurement axiomatizations underlying probabilities. Moreover, according to authors such as Musvoto, (2008, 2011), Ryan, Scapens and Theobald (2002), Stamp (1981) and Tinker (1985), it is generally agreed in the accounting literature that value is inherently a property in flux. They argue that the accounting literature does not provide a full empirical description of value. Thus, if this is the case, with respect to the concept of a random variable, it is difficult to point out exactly what causes the variability of the value. Musvoto (2011) also highlights that it is inappropriate to represent economic events with numbers as this places the variability at the cardinality level, rather than within the empirical relational structure. Therefore, it follows that to find a way of representing economic events that preserves their variability, if at all, they are random variables.

\section{PROBABILITY AND RANDOM VARIABLE REPRESENTATIONS IN ACCOUNTING AND FINANCE}

In this section the problems of representing perceived random variables in accounting and finance with probability distributions will be addressed using the random utility technique. According to Haugens (2001), the current perception in accounting and finance is that occurrences of accounting and finance phenomena are individual, concrete and independent instances of the same ideal norm. In this case, a finite sample of accounting and finance phenomena is defined as a random set. This gives the impression that the individual outcomes of instances cannot be predicted but one can hope to understand their long-run behavior. Velleman et al. (2010) also argues that the individual outcomes of random phenomena cannot be predicted, but one can hope to understand characteristics of their long-run behavior. This means that the outcome of each trial is not predictable, but over a long period of time it is understandable, i.e. one cannot know whether the next trial will result in the desired outcome but over a long period the percentage of the desired outcome will settle into a pattern. Consequently, with regard to the argument above, it is believed that the long-run behavior of accounting and finance phenomena can be predicted. Contrary to this belief, Musvoto and Scrimnger -Christian (2010) argues that the term "ideal norm" refers to the selection of a theory and a set of experimental conditions. He further points out that each occurrence of economic phenomena is unique. As a result, the problem in social scientific disciplines, such as accounting and finance, lies in the definition and selection of uniform experimental conditions of all occurrences of accounting and finance phenomena, i.e. given the uniqueness of each occurrence it is difficult to define uniform experimental conditions for all accounting and finance phenomena. Hence, in light of the above shortcomings a new approach to defining accounting and finance phenomena is needed. 
From the discussion above, it is clear that the accounting and finance phenomena do not fit the criteria of random phenomena in a way that facilitates the application probability theories applicable to events in such a class, i.e. for perceived independent events, one cannot depend on the law of large numbers that states that "if events are independent, the long-run relative frequency gets closer and closer to a single value" (Velleman et al., 2010, p. 88). This means that the occurrence of accounting and finance phenomena cannot be considered to be a trial or an attempt that generates an outcome that can be combined with outcomes of the occurrences of accounting and finance phenomena to form events. According to Velleman et al. (2010), the concept of independence when defining a sample space means that the outcome of one trial does not influence or change the outcome of another. If this is the case, it is debatable, for example in finance, whether the occurrence of a particular rate of return at a particular point in time does not influence the occurrence of another at a different point in time. Velleman et al. (2010) further point out that the concept of relative frequency is based on repeatedly observing the event's outcome and as a result this definition of probability is often called empirical probability. With regard to the concept of return in finance, it may be argued that before it is suggested that different occurrences of rates of return are identical, it is necessary to verify that they are truly identical. It is therefore necessary to ask ontological questions about the definition and occurrence of an economic event. Authors such as Musvoto and Gouws (2010), Musvoto and Scrimnger-Christian (2010) and Musvoto (2011) argue that ontological questions about accounting and finance phenomena have not been adequately addressed in these disciplines. As a result, there is a proliferation of opinions on what constitutes an accounting or a finance event. The appropriateness of using deterministic models in the accounting and finance disciplines is therefore debatable.

Following the discussion above, it is necessary to focus and discuss the possibility that the potential of occurrence of events in accounting and finance is based on subjective probability. According to Velleman et al. (2010), subjective or personal probability arises when an assessment of an event expresses personal uncertainty about the outcome. It is argued that although personal probabilities may be based on experience, they are not based on either long-run relative frequency or on equally likely events. When this is applied to accounting and finance, it may be argued that the probability concept applicable to accounting and finance is subjective probability, e.g. the IASB (2009) points out that an element of the financial statements must have a cost or value that is measurable if it is to be recognized in the financial statements. This suggests that the occurrence of accounting events is defined by them meeting the definition of an element of the financial statements and the outcome is defined by the measurability of cost or value. If cost or value is not measurable, it may be suggested that an event would be judged not to have occurred. However, according to Musvoto (2011) and Musvoto and Gouws (2010), value or cost is a subjective concept that has not received full measurement analysis, suggesting that the outcome of an accounting event is personal and cannot be based on a shared experience. Furthermore, Musvoto and Scrimnger-Christian (2010) points out that the concept of rate of return is a subjective concept that does not have a specifiable empirical relational structure. If this is the case, it may be argued that the event itself is not known in the finance discipline. Thus, it may be further argued that although personal judgment is used in determining the probabilities associated with the cost or value of accounting phenomena, based on the experience of the experimenter, these probabilities are not based either on long-run relative frequency or on equally likely events, because the definitions of the costs or values of accounting or finance phenomena are not known.

On the other hand, the subjective nature of the probability judgments in accounting and finance can be addressed through the probability biclassification concept using the random utility technique. Suck (1997) states the random utility technique as follows:

Given a set $\boldsymbol{A}$ of objects and a set $\boldsymbol{B}$ of properties which each $\boldsymbol{a} \in \boldsymbol{A}$ may or may not exhibit, subjects are asked to judge which properties of $\boldsymbol{B}$ an element of A has. Ideally, the classification of one subject should be consistent in the sense that if he or she ascribes property $\boldsymbol{b}$ and $\boldsymbol{b 1}$ to $\boldsymbol{a}$ and $\boldsymbol{b}$ to $\boldsymbol{a 1}$ then $\boldsymbol{a l}$ should also have the property $\boldsymbol{b} 1$. (p. 57)

This extract highlights the concept referred to as probability biclassification. Suck (1997) highlights that experience demonstrates that a single subject will not be consistent with regard to a biclassification and that different subjects will not agree on a classification. With regard to the accounting and finance discipline, this extract highlights that a single observer will not be able to make similar judgments about a situation even if it was repeated. As a result, with reference to the classification of the different rates of return of a stock over a period of time, equally likely events are in contrast to the concept of probability biclassification. If each individual cannot be 
consistent, then the particular event cannot be reproduced identically, if it is based on human judgment whereby it is known as an event for an individual. In this situation it is clear that the classical probability theory breaks down. In order to solve this problem, it may be suggested that each occurrence of an economic event be seen as an unquantifiable unique instance of an economic event. In this regard, economic events would cease to be represented by numbers. According to Musvoto (2011), numbers are constant random variables. Hence, thinking of economic events as unquantifiable or as not being able to be represented on the real line means that the full behavior of economic events is preserved. Therefore, the financial information is not limited to what the observer has been able to quantify. This problem can also be solved using the random utility theory. Suck (1997) describes the random utility theory or Thurstonean scaling as follows:

Random utility theory was devised to explain paired comparison data which consist of a $n \times n$ matrix $p$. The entry $p$ $(i, j)$ is the probability or the relative frequency with which stimulus $j$ dominated stimulus $i$ (or was preferred to stimulus $i$ ). Each $p(i, j)$ is an observed value determined in a series of choice experiments (all independent) and the scaling of the stimuli consists of assigning a random variable Ui to $i$ such that

$p(i, j)=P(U i<U j) .($ p. 57)

In relation to this extract it is recommended that judgments in accounting and finance should be provided in terms of paired comparison experiments in line with the random utility theory. In the excerpt, the random utility theory is used to represent outcomes of events in Bernoulli trials. Thus, for example in finance, in determining the expected rate of return over a period of time paired comparisons of the judgments of outcomes over the period of time should be used in a way comparable to the random utility theory. In accounting the same technique should be used before monetary units are assigned to the values of the elements of the financial statements. In this way, when the outcomes are compared, then analysis can be made to see whether they agree. Hence, a better judgment of the value of economics can be made.

\section{THE INTENTIONALITY STRUCTURE OF THE ACTS OF KNOWLEDGE IN ACCOUNTING AND FINANCE}

In the sections above it has been noted that probability laws have been applied to accounting and finance under the impression that human knowledge of the particulars of accounting and finance is able to give answers presupposed by the activities of inquiry and questioning in the disciplines. It is important to note that the application of laws, such as mathematical, probability or any other law, to a situation automatically presupposes that the situation is worthy of their application. In the view of the discussion above, the application of the probability law of expectation in determining the expected future economic benefits from an asset implies that the knowledge of the inquiring person about the world of an asset is complete in the context of the question. This suggests that before the enquirer calculates the expected economic benefits from an asset, it is necessary to know whether the cost or value of an asset is measurable. This would lead the enquirer to finding out whether cost or value meet the criteria of random phenomena whose occurrence is uncertain. However, the attitude towards inquiry about the uncertainty of occurrence of phenomena in accounting and finance does not question what is already given in experience. It only focuses on what is covered explicitly by the question and completely ignores what the question presupposes. Such presuppositions are reflected by Haugens (2001) in the following statement:

We might ask, for example, what is the probability of getting a rate of return in the next month that is less than zero? If we explore questions like this thoroughly, we may be able to envision what is called a simple probability distribution for the investment. The simple probability distribution shows the probabilities of getting various rates of return over the course of some period of time, in this case a month. (p. 32)

It is clear from the above that the question presupposes that a simple probability distribution can be used to find the probability of getting a particular rate of return in a particular period. This question assumes that the rate of return of a security is a random variable that can be represented by a simple probability distribution. However, according to Musvoto and Scrimnger-Christian (2010), this assumption is incorrect. Musvoto and Scrimnger Christian (2010) argues that the rate of return on a security is constructed from the accounting concept of value that has not received full measurement analysis. For this reason it is not possible to establish the empirical validity of the structure of value. According to Heelan (1965), human intentions to knowing must be invariant elements in the 
structuring of the broad field of human activity, which as far as the active and enquiring person is concerned, is presupposed by the activity of doing and questioning. This means that the orientation of the enquiring mind must be impersonal in seeking answers to questions. It must embrace the world as being prior to the elements and give reality to the elements.

The current orientation of the enquiring mind is towards the maintenance of what may be termed "the cult of impersonality" in accounting and finance. According to Heelan (1994), the theory of probability arose as a way of measuring rational belief in conditions of uncertainty. This means that the mathematization of the concept of probability in accounting and finance is to permit the evaluation of information to fixed quantitative rules. This has lead to the neglect of the viewpoint that the accounting and finance worlds are also subject to unconstrained judgment that invites arbitrariness or bias. Heelan (1965) defines subjectivity as follows:

We define subjectivity to be the absence of the corresponding kind of objectivity. Subjectivity then is a word with many meanings which are differentiated by the types of objectivity defined. (p. 7)

If this is the case, it follows that probability laws should not be applied in accounting and finance in a way that cultivates and gives an impersonal view to information, but rather in a way that takes into account the unconstrained judgments that invite arbitrariness or bias. For example, as a guideline, the IASB (2009) framework for financial reporting points out that users must be able to compare financial statements of different entities in order to evaluate their relative financial position, performance and changes in financial position. It follows then, that the application of probability laws to this guideline should not be taken to mean that information in the financial statements is free from all subjectivity, rather its objectivity should be given in context. The guideline reflects two perspectives to comparability, i.e. firstly, comparability is given as an idea or concept in a public domain and secondly, comparability is given as it makes an appearance in a world of the real, with financial statements acting as factual judgments or descriptions of accounting objects. The first perspective gives comparability as an exact and precise accounting definition that is independent of particular places and factual occurrences. However, the concept of comparability is just an idea, i.e. the ontological questions that give knowledge about the being of comparability in accounting have not been addressed appropriately by the accounting literature. The outlook of the accounting concept of comparability implies certain philosophical doctrines about objectivity, reality and deterministic theories. In advocating comparability, accounting implies that accounting phenomena have empirical objectivity. Heelan (1965) points out that in cases of empirical objectivity the relationship between noema and noesis is one of exteriority with respect to the knowing subject. This means that in relation to accounting, for most accountants the physical real in the discipline is a body situated outside them and outside all observers in a determinate part of space and time. Hence, economic events in this respect are regarded as composed of structures that can be represented in a determinate fashion. Consequently, from the perspective of accounting comparability such representations would answer the ontological questions in the discipline. It is true that economic events are empirical and are represented by empirical data based on models and theories. However, ontological questions on economic events have not been addressed on the foundational level. The identification of exactly what underlies empirical data, theories and models in accounting has not been addressed. Some authors (e.g. IASB, 2009; Wolk, Teamey \& Dodd, 2002) have argued that the foundations of economic exchanges are based on the measurement of value. In spite of this assertion, no clear empirical description of value has been given in the accounting literature. After noticing the lack of an unambiguous description of value, authors such as Musvoto and Gouws (2010), Ryan et al. (2002) and Stamp (1981) argue that there is no specifiable relationship between monetary units and value. In this case, this means that value cannot be given in perception, but it can still be thought about. Hence, value becomes an ideal body, i.e. the content of a concept constructed as a limiting case of what can be given in experience. According to Heelan (1965), there are two limiting cases of what can be experienced of the physical real in a determinate part of space and time: a classical particle and a classical field. The classical particle has position, but no magnitude, while the classical field is conceived to be an infinitely extended medium like a hypostatised space with just sufficient body to sustain vibration motions. The concept of value is perceived to have magnitude that is measured in terms of monetary units. Moreover, from Debreu's (1959) value theory, the concept of value is defined from the perspective of a value space. In this case, the economic activities that occur at a specific time in this space define value. Hence, from this argument the concept of value in accounting may be viewed from the perspective of having a combination of the qualities of a classical particle and a classical field. If this is the case, it follows that value is a physical object. Heelan (1965) notes that physical objects are linked by some kind of causality, which regulates their appearances in 
strict and orderly sequences of antecedent consequents. This kind of causality removes personal views of the enquirer about the physical object. It is clear therefore that if the accounting discipline value is embodied by qualities that do not reflect the personal views of the enquirer then, it inhibits the physical law of causality. The law states (Heelan, 1965), "When all determinations which describe the present state of an isolated system are known, then the future of the system can be calculated" (p. 26).

This quotation highlights that predictions can only be made if the complete present behavior of an isolated system is known with certainty. Assumptions in accounting presume that the complete present behavior of an accounting phenomenon is known with certainty. For example, forecasts and expectations are used in the preparation of the financial statements for both internal and external reporting, i.e. forecasts and expectations are used to predict the future states of economic phenomena (Horngren, 1982; IASB, 2009). This suggests that it is believed in the accounting discipline that the long-run behavior of economic events can be predicted. Similarly, in the finance discipline, it is believed that economic events exhibit the physical law of causality. For example, Haugen (2001) points out that in investment theory the simple probability distribution is used to show the probabilities of getting various rates of return over the course of a particular period of time, e.g. a month. This reflects that the longrun behavior of the rates of return on a security can be predicted. In this case, one has to know all determinations, which describe the present state of the return on a security. In other words, it is necessary to fully understand the empirical data describing the return on a security, the theory underlying the empirical data and the foundations underlying the theories that describe the empirical data. If, as argued above, the economic events exhibit the physical law of causality then it follows that they can be represented conceptually in the same way by everyone. In this case, economic events would possess a determinate description or definition that leaves no element to be completed by private acts of observation.

If, as discussed above, the intention of the accounting and finance disciplines is to give economic events the qualities that make them representable conceptually in the same way by everyone, then, the disciplines are not doing a very good job of it. In fact, the disciplines display a confused notion of determinism. It is purported that value is representable by monetary units in an infinitely precise conceptual way. For example, the IASB (2009 defines accounting measurement as the assignment of monetary units to the elements of the financial statements. However, no discussion of error is made in the conceptual framework. Musvoto and Scrimnger -Christian (2010) also notes that there is no specification of how the concept of error should be dealt with in accounting measurement models. Therefore, one cannot purport to measure an entity in an infinitely precise way when the measurement that occurs in the real world is not as an abstract norm. In the real world, precision is only up to a certain degree.

\section{CONCLUSIONS AND RECOMMENDATIONS}

In this study, it has been highlighted that economic events are treated as random variables in a way that is not consistent with probability theories. As a result, probability theories are applied to accounting and finance data to produce information that may not be useful to users. Furthermore, this problem is made worse by the fact that acts of knowledge inquiry in accounting and finance do not focus on what is presupposed by the question. Prescriptions are made in this study to address the problem of the randomness of accounting and finance phenomena.

A recap of some of the main points is given below:

- $\quad$ Studies in accounting and finance highlight that accounting and finance concepts are defined in a way that is vague and ambiguous. As a result, it is difficult to know the empirical properties of accounting and finance phenomena.

- It has been argued that the normal probability distribution is not suitable for determining the expected rate of return of a security over a period of time.

- The methods of enquiry used in accounting and finance do not question what is already given in experience. They only focus on what is covered explicitly by the question, and completely ignore what the question presupposes.

In view of the above, the concepts of probability biclassification and random utility theory are recommended to solve the problem of placing randomness at the cardinality level rather than at the level of the empirical relational structure. 


\section{AUTHOR INFORMATION}

Charmaine Scrimnger-Christian is a lecturer in Statistics at the School of Information Technology of the NorthWest University, Vaal Triangle Campus. She is also involved in statistical consultation for postgraduate students. Her research interests include Operational Research, Risk management, Conceptual knowledge systems, Multilevel Statistical Analysis and Statistics. E-mail: Charmaine.ScrimngerChristian@nwu.ac.za. Corresponding author.

Dr Musvoto is a senior lecturer in Financial Management and Accounting at the School of Accounting Sciences of the North-West University's Vaal Triangle Campus. He received his PhD from the University of Pretoria in 2008. Dr Musvoto is also affiliated with the Association of Chartered Certified Accountants and the Chartered Institute of Management Accountants. His research interests include accounting measurement, risk management and the implications of modern principles of measurement on finance theory development. E-mail: 22838082@nwu.ac.za

\section{REFERENCES}

1. Black, F., Jensen, M. C., \& Scholes, M. (1972). The Capital Asset Pricing Model: Some Empirical Tests. In M.C. Jensen (Ed.), Studies in Theory of Capital Markets. New York: Praeger

2. Debreu, G. (1959). Theory of value: An axiomatic analysis of economic equilibrium. New Haven and London: Yale University Press

3. Falmagne, J-C. (1979). On a class of probabilistic conjoint measurement models: Some diagnostic properties. Journal of Mathematical Psychology, 19(2), 73-88.

4. Falmagne, J-C. (1980). A probabilistic theory of extensive measurement, Philosophy of Science, 47(2), $277-296$.

5. Haugens, R. A. (2001). Modern investment theory. $5^{\text {th }}$ edition. New York: Prentice Hall.

6. Heelan, P. A. (1965). Quantum mechanics and objectivity. The Hague: N Nijioff.

7. Horngren, C. (1982). Cost accounting: A managerial emphasis. $5^{\text {th }}$ edition. Englewood Cliff, New Jersey: Prentice Hall.

8. International Accounting Standards Board (IASB). (2009). International Financial Reporting Standards (IFRS), (2009): Including International Accounting Standards (IAS) and interpretations as at 1 July 2009. Vol 1A \& Vol 1B. London: IASB.

9. Michell, J. (1986). Measurement scales and statistics: A clash of paradigms. Psychological Bulletin, 100, 398407.

10. Musvoto, S. W. (2008). Applying the representational theory of measurement to accounting. (Doctoral thesis, University of Pretoria, viewed 2010-12-11< http://upetd.up.ac.za/thesis/available/etd-03282009$125051 />$ D565/ag

11. Musvoto, S. W. (2011). Implications of the crisis of objectivity in accounting measurement on the development of finance theory. International Business \& Economics Research Journal, 10(2), 113-122.

12. Musvoto S. W., \& Gouws D. G. (2010). The concept of a scale in accounting measurement. South African Journal of Economic and Management Sciences, 13(4), 424-436.

13. Musvoto, S. W., \& Scrimnger-Christian, C. (2010). The statistics of finance, measurement and accounting information. Proceedings of the International Conference on Finance, IEEE Catalogue number: CFP 1051MPRT, ISBN: 978-1-4244-9547-4, IEEE-2010.

14. Ryan, B., Scapens, R. W., \& Theobald, M. (2002). Research method and methodology in finance and accounting. Second Edition. Mitcham, Surrey: Padstow Cornwall

15. Stamp, E. (1981). Why can accounting not become a science like physics? Abacus, 17(1), 13-27

16. Staubus, G. J. (2004). Two views of accounting measurement. Abacus, 40(3), 265-279.

17. Stevens, S. S. (1951). Mathematics, measurement and psychophysics. In (Ed.), Handbook of Experimental Psychology. New York: Wiley.

18. Suck, R. (1997). Probabilistic biclassification and random variable representations. Journal of Mathematical Psychology, 41, 57-64.

19. Tinker, T. (1985). Paper Prophets, A Social Critique of Accounting. New York: Praeger.

20. Velleman, P.F., Sharpe N.R., De Veaux, R.D (2010). Business Statistics, Pearson Education, Inc., Upper Saddle River, New Jersey, 07458

21. Wolk, H. I., Tearney, M. G., \& Dodd, J. L. (2001). Accounting theory: A conceptual and institutional approach. South Western College Publishing

22. Zebda, A. (1991). The problem of ambiguity and vagueness in accounting, Behavioral Research in Accounting, $3,117-145$ 